\title{
WAITING FOR CHRONOMATIC
}

\section{There's always time.}

\section{BY JEFF HECHT}

$\mathrm{I}$ had almost given up hope, when the Chronomatic technician arrived at my little furnished flat in the twenty-first century. Four days had passed since both my Chronomatic Communicator and the Transporter itself had failed.

That was not supposed to happen. "Nobody ever gets lost in time with Chronomatic," the reviews said. If a Chronomatic Transporter failed, the Communicator could call help. Both would never fail, the sales bot had assured me, and authorized Chronomatic service technicians were available any place and any time that I might visit.

Sure enough, the Chronomatic emergency help number was on a pad next to the chronologically correct black telephone in my flat. After several minutes figuring out how to manipulate its silly antique dial, I was speaking with a bot, but it was so stupid that all it could do was say that Chronomatic would dispatch the first available technician if I left my name and location. Calling again reached the same robot, which said exactly the same thing.

I could only wait, taking short walks to get food, and killing time reading Wikipedia and watching YouTube on a dusty iPad. I was watching a Comcast technician sleeping on a couch when the doorbell finally rang. The short dark woman standing outside wore a blue Chronomatic Transport shirt, and carried a large shiny toolbox.

She apologized for the delay. "I am the only tech on call-down now, and I had to drive all the way from Kansas City. But there's always time."

"There's always time," I recalled, was Chronomatic's slogan.

I told her what had happened, and she sat on the couch, setting her toolbox on the coffee table. I watched from the armchair as she tested and probed the Transporter and Communicator. They did nothing. She got more tools from her van, and tested and probed some more.

Finally she looked at me, shrugged and said: "They're in a death loop."

"Can you fix it?"

"Of course not. It's a death loop. They are sending signals that make each other freeze."

"I pushed the reset before I called," I said.

“That didn't do any good. It never does.

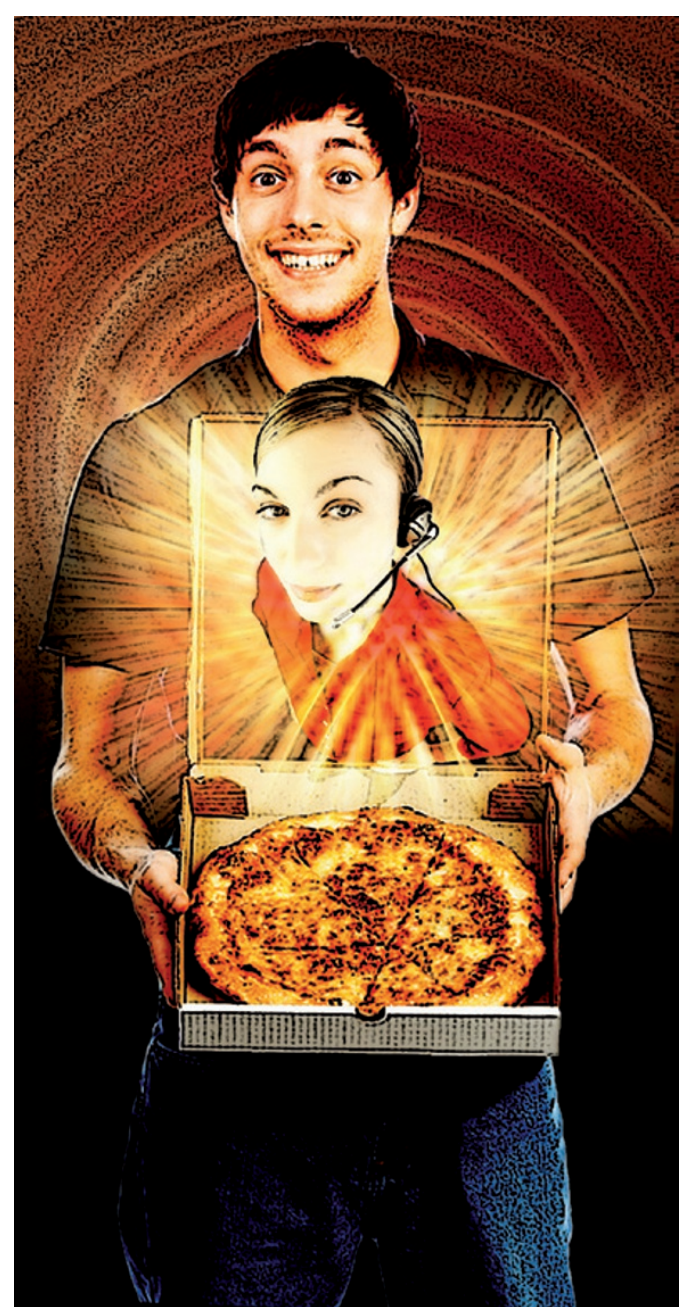

It's a twenty-fourth century mistake; we can't fix it here."

I said something very impolite.

"Don't panic. I have replacement units in the van. All I have to do is call headquarters on my Communicator so that they can key in your ID and authorization codes for the new units. It won't take long once I get through."

She returned with a shiny new Transporter and a jet black Communicator. Their cases opened to show the screens, and I watched her wait for the start-up display. When all was ready, she sat on the couch and opened a Communicator that looked older and more worn than mine.

"Get me technician authorization trans- $\rightarrow$ NATURE.COM

Follow Futures on

Facebook at:

go.nature.com/mtoodm fer," she told the Communicator.

It beeped once, then beeped again. I watched and waited.
"Still seeking connection," the Communicator said. It repeated the message ten more times before she cancelled the call to try again.

"Priority request. Technician requesting transfer of authorization to replacements for death-loop units," the technician said. This time it beeped twice, then announced: "Making connection."

I relaxed in the armchair. After four days, I could wait a few more minutes.

Half an hour passed. The Chronomatic technician sighed. "It sometimes takes a while."

I dozed off, waking with a start when I heard her talking. "I asked for the technician transfer-of-authorization line," she said, rather loudly. "What do you mean you don't do that any more?" She listened for a moment. "Go ahead and transfer me, then," she said, shaking her head.

Realizing that I was awake, she turned to me. "Wrong office. They reorganized support again, and didn't bother to tell anybody down in the twenty-first century."

This time she waited longer. The sun set, and I went out and got a pizza. She slipped a headset on while we ate. I stuck the last slice into the little refrigerator, to have for breakfast. When I came back she was talking to someone.

"His Transporter and Communicator are locked in a death loop. We're in the twenty-first century, and I cannot repair it," she said, rolling her eyes at me. "So who should I talk to?"

When she was finished, she put her communicator on the couch, stretched and said she needed to use the bathroom.

"Another office handles death loops," she said when she returned, and recited a new request. The communicator beeped twice, then announced: "Connection established. Please wait for the next available assistant. Estimated hold time 4 hours."

She shrugged and stretched out on the couch.

"Why can't a time-travel company route calls through time so they arrive when somebody is there to answer them?" I asked.

"Because they're a corporation," she said, and closed her eyes.

It is now 48 hours and counting. A Chronomatic technician is sleeping on my couch.

Jeff Hecht is Boston correspondent for New Scientist and a contributing editor to Laser Focus World. 